\title{
RANCANG BANGUN APLIKASI PUSAT INFORMASI SEKOLAH DENGAN PENERAPAN CHATBOT MENGGUNAKAN AIML BERBASIS ANDROID PADA SMK OTOMOTIF AL HUSNA TANGERANG
}

\author{
Ryan Zulham Ramadhani ${ }^{1}$, Hengki Rusdianto ${ }^{2}$, Viky Yahya ${ }^{3}$ \\ Program Studi Informatika \\ Fakultas Teknik Universitas Muhammadiyah Tangerang \\ Jl. Perintis Kemerdekaan 1/33 Cikokol Kota Tangerang \\ Ryan.zulham@umt.ac.id ${ }^{1}$, Hengki.Rusdianto@gmail.com², , viky yahya.id@gmail.com³
}

\begin{abstract}
Abstrak - Dengan adanya teknologi informasi yang semakin maju, tentu sangat membantu manusia dalam membuat,mengubah,menyimpan dan mencari informasi. Proses pencarian informasi di SMK Otomotif Al Husna dilakukan dengan cara mencari brosur sekolah, mading sekolah atau langsung datang dan bertanya ke pihak sekolah. Penelitian ini bertujuan untuk membangun aplikasi android dengan penerapan chatbot. Pada perancangan aplikasi chatbot ini menggunakan Artificial Intelligence Markup Languange (AIML) sebuah bahasa untuk menyusun logika pada chatbot. Bahasa scripting interpreter yang merupakan turunan dari Extensible Markup Language (XML) dengan fungsi yang lebih spesifik. AIML digunakan sebagai basis pengetahuannya (knowlage base) dengan mengelola data knowlage base menggunakan database MySQL. Metode dalam pengembangan sistem menggunakan metode extreme programming sedangkan metode dalam pengumpulan data adalah studi pustaka, observasi dan wawancara. Dengan pemanfaatan chatbot yang telah dilengkapi dengan kecerdasan buatan dan informasi berupa audio, membuat pengguna lebih mudah mendapatkan informasi tentang sekolah yang berasal dari basis data dan pengguna dapat memperoleh informasi tentang sekolah dimanapun dan kapanpun.
\end{abstract}

Kata kunci : Pusat Informasi Sekolah, Chatbot, AIML, MySQL

1. PENDAHULUAN

a. Latar Belakang Masalah

Perkembangan teknologi pada saat ini sangat cepat dan hampir menyeluruh disemua kalangan dan semua bidang, hal ini ditandai dengan banyaknya pengguna komputer dan smartphone, baik untuk kepentingan perusahaan, pendidikan dan kesehatan. Informasi berperan sangat penting pada era globalisasi pada saat ini. Semua aktivitas dalam kehidupan membutuhkan informasi, sehingga semua aktivitas yang dijalankan dituntut untuk menghasilkan informasi yang berguna bagi setiap orang.

Perkembangan teknologi akan terus meningkat, di Indonesia sendiri perkembangan chatbot telah banyak diterapkan oleh berbagai perusahaan untuk menunjang pelayanan konsumen. Chatbot merupakan suatu aplikasi yang dirancang untuk berkomunikasi antara manusia dengan mesin. Program chatbot mampu memberikan kepuasan penggunanya dengan kemampuannya merespon berbagai pertanyaan yang berbeda-beda dengan cepat. Chatbot memiliki kemampuan dalam menyimpan informasi tanpa melupakan satu pun informasi yang disimpan dan digabungkan dengan kepraktisan dalam mencari dan memberi informasi. Sudah saatnya chatbot ini diimplementasikan di dunia pendidikan untuk membantu Berdasarkan observasi yang dilakukan di SMK Otomotif Al Husna, masyarakat atau orang yang ingin mendapatkan informasi mengenai sekolah harus mencari lewat brosur, mading sekolah atau langsung bertanya kepada pihak sekolah melalui telepon atau datang langsung ke sekolah untuk bertanya ke staf tata usaha di saat hari kerja. Dengan cara tersebut untuk mendapatkan informasi mengenai sekolah masih membutuhkan waktu dan biaya yang tidak sedikit. Pertanyaan-pertanyaan yang diajukanpun sering sama antar orang yang mencari informasi. Melihat keadaan dan realita yang ada, penulis terdorong untuk 
membuat suatu aplikasi chatbot berbasis android sebagai tugas akhir dengan judul "Rancang Bangun Aplikasi Pusat Informasi Sekolah dengan Penerapan Chatbot Menggunakan AIML Berbasis Android pada SMK Otomotif Al Husna Tangerang". Penerapan chatbot menggunakan AIML diharapkan dapat mengurangi biaya, menghemat waktu dan mempermudah pengguna(masyarakat) dalam mencari informasi yang terdapat di sekolah SMK Otomotif AI Husna.

\section{b. Identifikasi Masalah}

1. Membutuhkan waktu yang lama untuk mencari informasi mengenai sekolah.

2. Keterbatasan waktu dalam mendapatkan informasi-informasi tentang sekolah.

3. Pertanyaan-pertanyaan yang diajukan ke pihak sekolah sering sama.

\section{c. Rumusan Masalah}

1. Bagaimana merancang dan membangun aplikasi pusat informasi sekolah dengan penerapan chatbot yang dapat berjalan di Smartphone berbasis Android

2. Bagaimana memberikan kemudahan kepada pencari informasi saat mencari informasi-informasi yang berada di SMK Otomotif AL Husna Tangerang?

\section{d. Batasan Masalah}

1. Aplikasi pusat informasi sekolah dengan chatbot hanya dapat berjalan di smartphone android.

2. Aplikasi chatbot hanya menerima kata kunci atau perintah dalam bahasa Indonesia.

3. Kecerdasan buatan yang diterapkan pada aplikasi ini hanya berisi informasi mengenai sekolah SMK Otomotif Al Husna.

4. Dalam menggunakan aplikasi chatbot harus terhubung dengan internet.

\section{TINJAUAN PUSTAKA}

a. Chatbot

Chatbot, salah satu sistem cerdas yang dihasilkan dari pemrosesan Bahasa alami atau Natural Language Processing (NPL) yang merupakan salah satu cabang dari Kecerdasan Buatan atau Artificial
Intelligence. Sebuah program komputer yang dapat melakukan percakapan melalui media tulisan. Percakapan dapat terjadi dengan manusia atau chatbot yang lain. Chatbot pada dasarnya memiliki 2 komponen utama yaitu Chat yang dapat diartikan sebagai percakapan dan Bot merupakan sebuah program yang mengandung sejumlah data, jika diberikan masukan maka akan memberikan jawaban."(Ananda, Imamah, Andre, dan Ardiansyah, 2018).

\section{b. Artifical Intelligence Markup Language(AIML)}

Menurut Christianto, Siswanto, Chaniago (2016), AIML merupakan sebuah bahasa yang mendeskripsikan objek data dan perilaku program komputer yang memprosesnya. AIML sendiri merupakan turunan dari Extensible Markup Language (XML). AIML berisi kumpulan pola dan respon yang dapat digunakan oleh chatbot untuk penelusuran jawaban setiap kalimat yang diberikan.

\section{c. Android}

Menurut Nazruddin Safaat H (2012), Android adalah sebuah sistem operasi untuk perangkat mobile berbasis linux yang mencakup sistem operasi, middleware dan aplikasi.

\section{d. Android Studio}

Android Studio adalah sebuah IDE untuk Android Development yang diperkenalkan google pada acara Google I/O 2013. Android Studio merupakan pengembangkan dari Eclipse IDE, dan dibuat berdasarkan IDE Java populer, yaitu Intel IDEA. Android Studio merupakan IDE resmi untuk pengembangan aplikasi Android(Novitasari, Mustain dan wahyudi, 2017)..

\section{e. Codelgniter}

Menurut Raharjo (2018) Codelgniter adalah framework web untuk bahasa pemrograman PHP, yang dibuat oleh Rick Ellis pada tahun 2006, penemu dan pendiri EllisLab (www.ellislab.com). EllisLab adalah suatu tim kerja yang berdiri pada tahun 2002 dan bergerak di bidang pembuatan software dan 
tool untuk para pengembang web. Sejak tahun 2014 sampai sekarang, EllisLab telah menyerahkan hak kepemilikan Codelgniter ke British Columbia Institute of Terchnology (BCIT) untuk proses pengembangan lebih lanjut.

\section{f. Diagram SIPOC}

Menurut Gaspersz (2010) dalam Tugas Akhir Yudi Hasbulah (2016) "Diagram SIPOC merupakan suatu diagram yang biasa digunakan dalam tahap define untuk memberi gambaran secara umum terhadap proses yang ada saat ini. Diagram SIPOC (Supplier - Inputs - Process - Outputs Customer) adalah salah satu tools yang paling sering digunakan dalam penerapan Six Sigma atau peningkatan kuallitas."

\section{g. Artificial Intelligence}

Menurut Teahan (2010), Kecerdasan buatan yang biasa disingkat AI (Artificial Intelligence) merupakan ilmu tentang bagaimana membangun suatu sistem komputer yang menunjukkan kecerdasan dalam berbagai cara. Al merupakan area penelitian yang dinamis dalam topik riset ilmu komputer. Sampai saat ini, telah banyak penelitian mengenai perkembangan Al diantaranya neural network, evolutionary computing, machine learning, natural language processing, dan object oriented programming.

\section{h. Extreme Programming}

Menurut Usman dan Widayati (2014) dalam jurnal Adi Supriyatna (2018), Extreme Programming (XP) adalah metode pengembangan perangkat lunak yang sederhana dan mencakup salah satu metode tangkas yang dipelopori oleh Kent Beck, Ron Jeffries, dan Ward Cunningham. XP adalah salah satu metode tangkas yang paling banyak digunakan dan menjadi pendekatan yang sangat terkenal. Tujuan XP adalah tim yang terbentuk antara kursus berukuran kecil hingga menengah, tidak perlu menggunakan tim besar. Hal ini dimaksudkan untuk mengatasi persyaratan yang tidak jelas dan perubahan persyaratan dengan sangat cepat.

\section{i. $\mathrm{XML}$}

XML adalah bahasa markup yang menggunakan tag sebagai penanda untuk mengkategorikan, menjelaskan data lebih spesifik. Pada XML terdapat tag pembuka $<$ tag $>$ dan tag penutup $</$ tag $>$. Tag pembuka dan tag penutup hanya mempunyai perbedaan karakter / pada tag penutup. Fungsi utama dari XML adalah komunikasi antar aplikasi, integrasi data, dan komunikasi aplikasi eksternal dengan partner luaran. Dengan standarisasi XML, aplikasi-aplikasi yang berbeda dapat dengan mudah berkomunikasi antar satu dengan yang lain(Sudirman, 2016).

\section{j. Program-O}

Program-O (www.program-o.com), sebuah interpreter chatbot berbasis AIML yang ditulis menggunakan bahasa PHP. Interpreter ini dilengkapi dengan panel control untuk botmaster dalam mengelola pengetahuan chatbot yang meliputi penambahan pengetahuan dari file AIML ekstemal, pengeditan pengetahuan, dan lain-lain (suryani dan amalia, 2017).

\section{METODOLOGI PENELITIAN}

\section{a. Jenis Penelitian}

Pada penelitian ini digunakan jenis penelitian kualitatif dengan metode studi kasus. Penelitian kualitatif adalah penelitian yang bermaksud untuk memahami fenomena tentang apa yang dialami oleh subjek penelitian misalnya perilaku, persepsi, motivasi, tindakan dan lain-lain secara holistik dan dengan cara deskripsi dalam bentuk kata-kata dan bahasa, pada suatu konteks khusus yang alamiah dan dengan memanfaatkan berbagai metode alamiah.

\section{b. Tahapan Penelitian}
1) Identifikasi Masalah
2) Pengumpulan Data
3) Analisa Kebutuhan
4) Desain Sistem
5) Implementasi Sistem dan Testing
6) Pembuatan Laporan Tugas Akhir

\section{c. Metode Analisa Sistem}

Pada tahapan analisa sistem ini peneliti menggunakan diagram SIPOC (SupplierInputs-Process-Outputs-Customer), 
diagram ini memberikan gambaran secara umum terhadap proses yang ada saat ini.

\section{d. Metode Pengembangan Sistem}

Metode dalam pengembangan sistem ini menggunakan System Development Life Cycle (SDLC) dengan model proses Extreme Programming. Dengan tahapan sebagai berikut :
1) Planning
2) Design
3) Coding
4) Testing

4. ANALISA DAN IMPLEMENTASI

a. Gambaran Sistem Baerjalan

Dari hasil wawancara dan observasi yang telah dilakukan, penulis menggambarkan sistem yang berjalan dengan flowchart sebagai berikut:

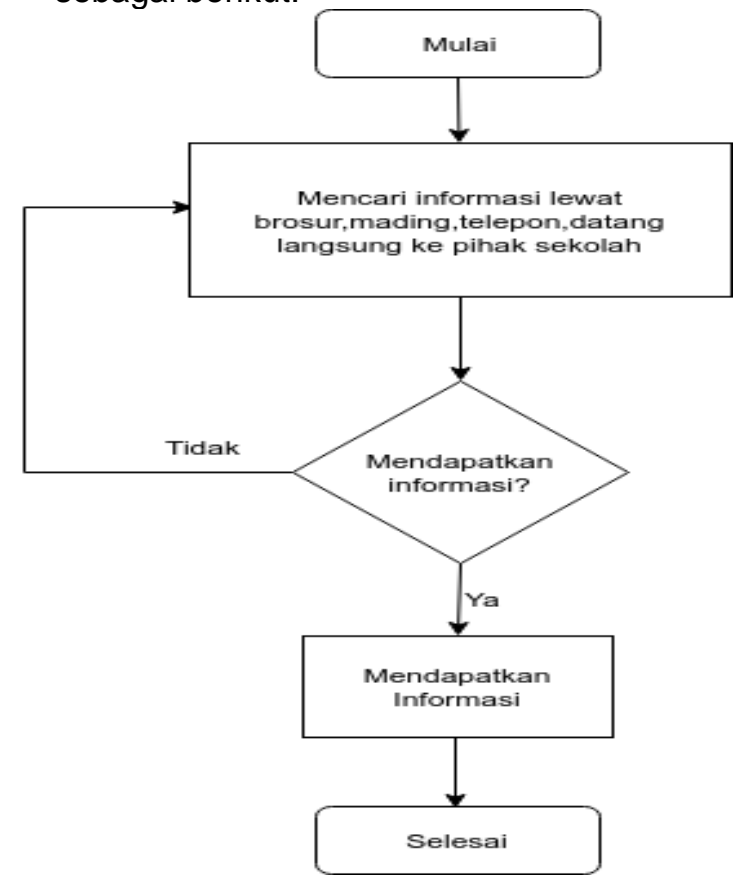

Gambar 4.1 Flowchart Sistem Berjalan

\section{b. Anallsa Diagram SIPOC}

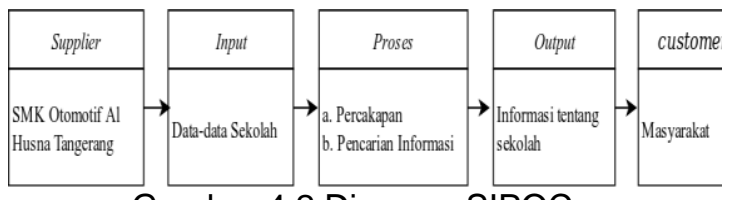

c. Desain
1. Unified Modeling Language (UML)

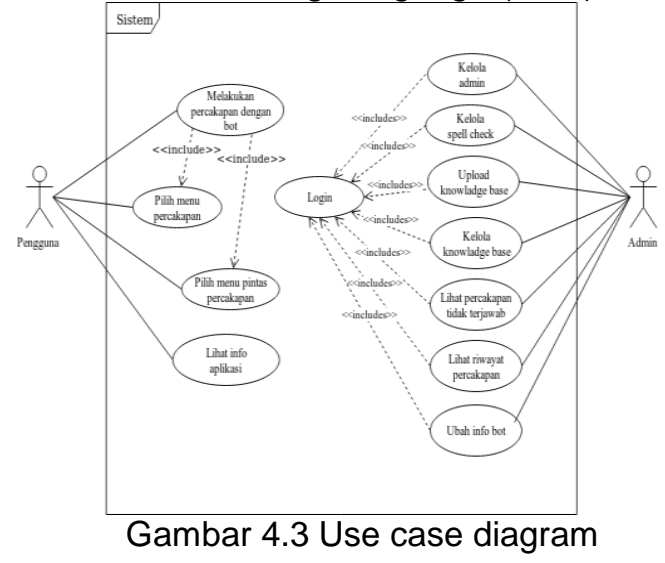

2. Activity Diagram

a. Activity Diagram percakapan dengan bot

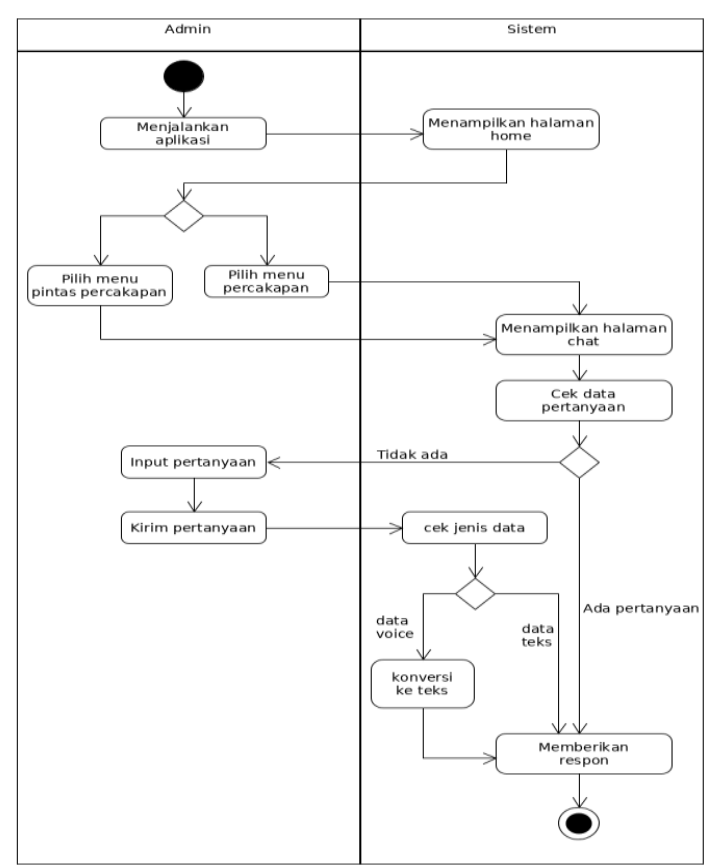

Gambar 4.4 Activity Diagram percakapan dengan bot

3. Class Diagram

a. Class diagram web admin 
Tangerang, November 2019

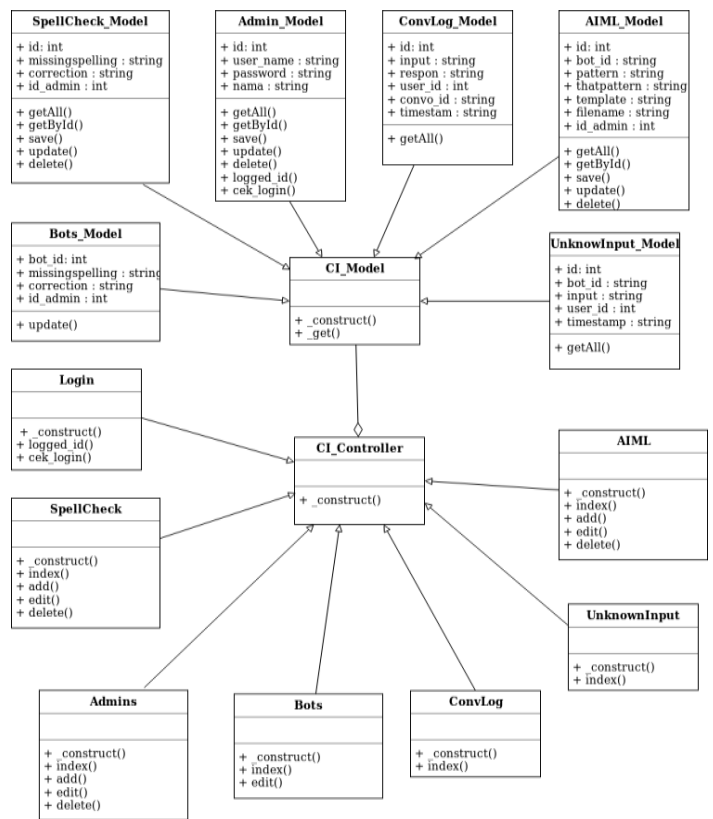

Gambar 4.5 Class diagram web admin

b. Class diagram aplikasi android

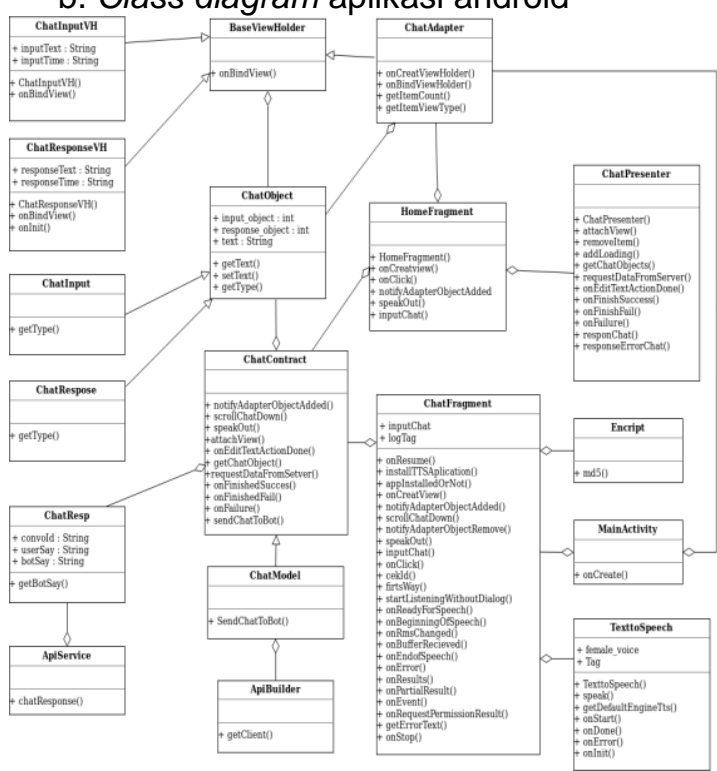

Gambar 4.6 Class diagram aplikasi android

\section{d. Implementasi}

Berikut ini merupakan implementasi sistem yang telah dibuat:

1. Tampilan halaman home aplikasi chatbot
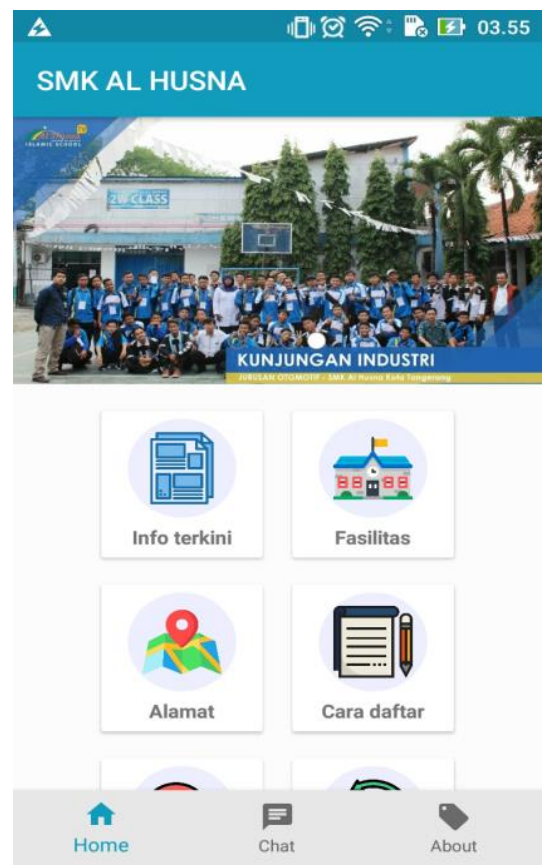

Gambar 4.7 tampilan halaman home aplikasi chatbot

2. Tampilan halaman chat

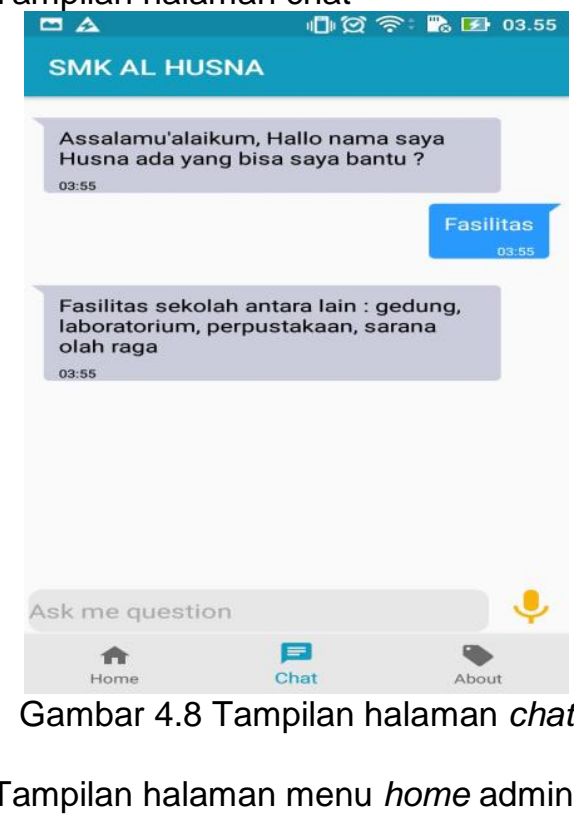

3. Tampilan halaman menu home admin 




Gambar 4.9 Tampilan halaman home admin

\section{Tampilan halaman kelola knowledge base}

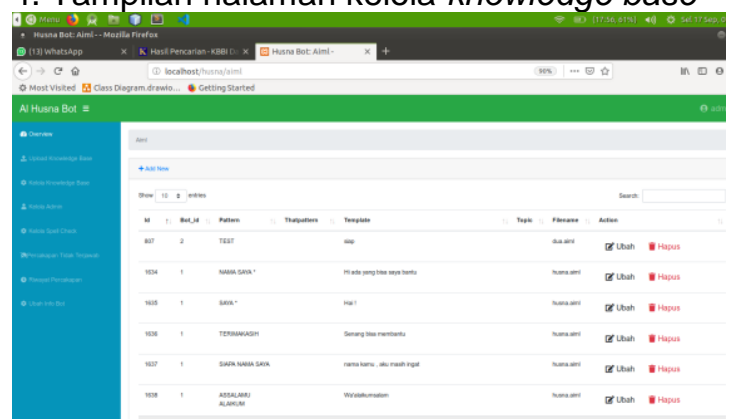

Gambar 4.10 Tampilan halaman kelola knowledge base

5. Tampilan halaman kelola knowledge base

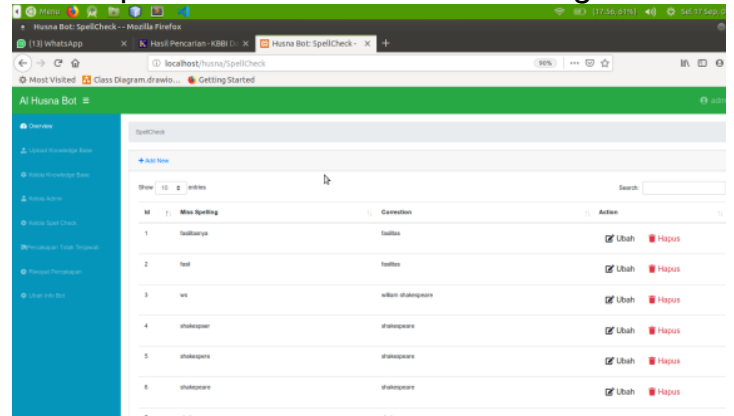

Gambar 4.11 Tampilan halaman kelola knowledge base

6. Tampilan halaman riwayat percakapan

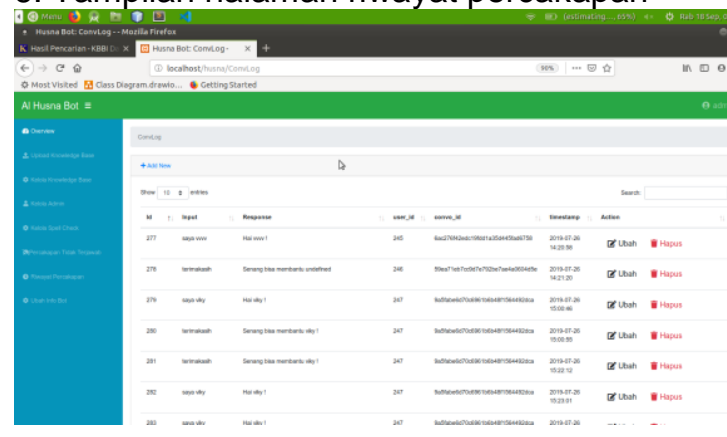

Gambar 4.12 Tampilan halaman riwayat percakapan

7. Tampilan halaman percakapan tidak terjawab

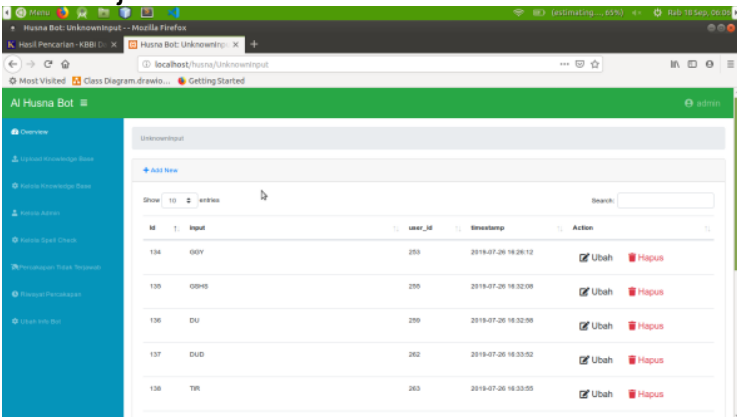

Gambar 4.13 Tampilan halaman percakapan tidak terjawab

\section{KESIMPULAN DAN SARAN}

a. Kesimpulan

Berdasarkan penelitian dan uraian yang telah penulis uraikan, maka dapat ditarik kesimpulan sebagai berikut:

1. Proses pembuatan aplikasi pusat informasi sekolah dengan penerapan chatbot menggunakan AIML dengan metode pengembangan sistem extreme programing, dengan beberapa tahapan yaitu observasi, perencanaan, desain, coding dan pengujian.

2. Dengan aplikasi yang diusulkan, pengguna dapat dengan mudah mencar informasi-informasi mengenai sekolah SMK Otomotif Al Husna Tangerang.

\section{b. Saran}

1. Perlu ditambah dan dikembangkan lagi mengenai pengetahuan-pengetahuan percakapan umum di dalam bot.

2. Perlu ditambah tipe respon dari bot seperti gambar,video.

3. Perlu ditambah fitur-fitur tambahan seperti pendaftaran dan cek nilai siswa.

\section{REFERENSI}

[1]. D. R, F. Imamah, Y. M. Andre, and Ardiansyah. (2018). Aplikasi Chatbot (Milki Bot) Yang Terintegrasi Dengan Web CMS Untuk Customer Service Pada UKM MINSU. J. Cendikia, vol. XVI, pp. 100-106. 
[2]. D. Christianto, E. Siswanto, and R. Chaniago. (2016). Penggunaan Named Entity Recognition dan Artificial Intelligence Markup Language untuk Penerapan Chatbot Berbasis Teks, J. Telemat., vol. 10, no. 2, p. 8.

[3]. Dhebys Suryani dan Eka Larasati Amalia. (2017). Aplikasi Chatbot Objek Wisata Jawa Timur Berbasis AIML. SMARTICS Journal Vol. 3, No. 2.

[4]. Ependi, Usman. Qoriani Widayati. (2014). Extreme Programming Study Method Case Study on Designing of Accounting Term Dictionary. International Conference on Engineering \& Technology Development, hh. 52- 55.

[5]. Gaspersz, Vincent. (2010). Pedoman Implementasi Program Six Sigma Terintegrasi dengan ISO $9001: 2000$, MBNQA dan HACPP,Jakarta : PT. Gramedia Pustaka UtGaspersz, Vincent. 2010. Lean Six Sigma for Manufacturingand Service Industries. Jakarta : PT. Gramedia Pustaka Utama.

[6]. Raharjo, Budi. (2018). Belajar Otodidak Framework Codelgniter. Bandung: Informatika Bandung.

[7]. Safaat, Nazruddin H. (2012). Pemrograman Aplikasi Smartphone dan Tablet PC Berbasis Android. Bandung: Informatika.

[8]. Sarli Novitasari, Mustain dan M.Hasan Wahyudi. (2017). Sistem Informasi Geografis Rental Mobil Berbasis Android di Kabupaten Lamongan . JTIIES Vol. 1 No. 1.

[9]. Sudirman. (2016). Analisis Komunikasi Data Dengan XML Dan JSON Pada Web Service. CESS (Journal Of Computer Engineering, System And Science) Vol 1, No 2.

[10]. W. J. Teahan, Artificial Intelligence - Agents and Environments, Bookboon, 2010. 